Tropical Journal of Pharmaceutical Research April 2016; 15 (4): 855-860

ISSN: $1596-5996$ (print); 1596-9827 (electronic)

(C) Pharmacotherapy Group, Faculty of Pharmacy, University of Benin, Benin City, 300001 Nigeria.

All rights reserved.

Available online at http://www.tjpr.org

Original Research Article

http://dx.doi.org/10.4314/tjpr.v15i4.27

\title{
Pharmacists' knowledge and perception of topical antibacterial drug dispensing in community pharmacy setting in Kedah, Malaysia
}

\author{
Sathish Amirthalingam ${ }^{1 *}$, Rohit K Verma ${ }^{1}$, Jamuna R Appalasamy1, Ankur \\ Barura $^{2}$ and Kok Shin $\mathrm{Yi}^{3}$ \\ ${ }_{1}^{1}$ Department of Pharmacy Practice, ${ }^{2}$ Department of Community Medicine, ${ }^{3}$ Department of Pharmacy, International Medical \\ University, No. 126, Jalan Jalil Perkasa, 19, Bukit Jalil, 57000 Kuala Lumpur, Malaysia
}

*For correspondence: Email: asathish1981@gmail.com, SathishAmirthalingam@imu.edu.my; Tel: +6011 16185873

\begin{abstract}
Purpose: To assess Pharmacists' Perceptions and Experiences of Topical Antibacterial Drug Dispensing in Community Pharmacy Setting in Kedah State, Malaysia in order to minimize drug resistance issues.

Methods: A cross-sectional study involving a pre-validated questionnaire was conducted in community pharmacies within Kedah State, Malaysia. Descriptive statistics and Spearman's correlation coefficient were used for data analysis. The collected were analysed using statistical package for social sciences (SPSS) version 18.0.

Results: The result shows that, $53.4 \%$ of CPs in Kedah State perceived that topical antibacterial is not necessary for every topical bacterial infection. Fusidic acid was the most frequently dispensed topical antibacterial drug while superficial wound was reported to be the most frequently encountered topical bacterial infection. CPs (12.60\%) encountered antibacterial resistance cases but none reported them. The drug that had resistance issue was neomycin.

Conclusion: CPs in Kedah State, Malaysia generally have the right perceptions on the dispensing of topical antibacterial drugs. However, their knowledge on the rational use of topical antibacterial drugs and vigilance on antibacterial resistance issue need improvement.
\end{abstract}

Keywords: Topical antibacterial, Perception, Community pharmacists, Inappropriate antibiotic use

Tropical Journal of Pharmaceutical Research is indexed by Science Citation Index (SciSearch), Scopus, International Pharmaceutical Abstract, Chemical Abstracts, Embase, Index Copernicus, EBSCO, African Index Medicus, JournalSeek, Journal Citation Reports/Science Edition, Directory of Open Access Journals (DOAJ), African Journal Online, Bioline International, Open-J-Gate and Pharmacy Abstracts

\section{INTRODUCTION}

Skin diseases are among the most common health problem worldwide which affect around 30 to $70 \%$ of individuals in the United States [1]. Although most of the skin diseases are non-fatal, but they are considered to cause burden on health status as well as quality of life (QOL) [2]. Bacterial skin infection being one of them is usually caused by the invasion of pathogens through the skin flora [3]. In this case, topical antibacterial drug play a vital role to either kills or inhibits the growth of the bacterial [4]. Rod Tucker studied that, topical antibacterial drugs are commonly sought in the community pharmacies, with the empowerment of patient to self-medicate, CPs play a valuable role in gatekeeping these medications and ensure their proper usage $[5,6]$. The role played by CPs in gatekeeping these medications is very important as inappropriate usage of topical antibacterial 
drugs has been recognized as one of the factor that leads to antibacterial resistances [7].

According to $\mathrm{WHO}, \mathrm{CPs}$ should possess specific attitudes, knowledge and skills to support their roles in patient care [6]. Besides that, study also showed that proper and consistent patient counselling will result in the improvement of patient's understanding about the medication and consequently improve patient's adherence [8]. In short, CPs must be competent enough in dealing with topical antibacterial drugs as antibacterial resistances worsen by the lack of the development of more potent antibacterial drugs has urge the important to reserve the potency of existing antibacterial drugs $[9,10]$. Presently, very limited studies have been conducted on the way CPs dispense topical antibacterial drugs. Therefore, the objective of this study was to access the perceptions and experiences of CPS in Kedah state, Malaysia on the dispensing of topical antibacterial drugs.

\section{EXPERIMENTAL}

\section{Study design and population}

A cross-sectional study carried out using randomized sampling method. The study was conducted in Kedah State, Malaysia, from June to October 2014 with a validated selfadministered questionnaires were distributed to the CPs. A sample size of 101 participants was determined by Krejcie \& Morgan formula. However, 103 of CPs had participated in this study. CPs in Kedah, Malaysia, who have 2 years or more pharmacy practice experience and who volunteered to participate were included in this study.

\section{Questionnaire development and validation}

A questionnaire with three sections (demography of participants, perceptions of community pharmacists on the dispensing of topical antibacterial drugs and experiences of community pharmacists in the dispensing of topical antibacterial drugs) was developed and used as a data collection tools in this study. A pilot study was carried out among $30 \mathrm{CPs}$ to validate the questionnaire whose data were not included in this study.

\section{Ethical considerations}

IMU-Joint Committee of Research and Ethic Committee, International Medical University approved the study (no. BP I-01/11 (49) 2014).

\section{Statistical analysis}

Qualitative data obtained from this study was analysed using statistical package for social sciences (SPSS version 18.0) and analysed descriptively while open questions were coded into themes and analysed descriptively. The results are expressed in terms of frequencies, proportion, and percentages since categorical variables and Likert scales were used extensively in the questionnaires. Spearman's correlation coefficient was applied to analyze the degree of relationship between years of experience and confidence level. $P<0.05$ was considered statistically significant.

\section{RESULTS}

\section{Demographics of participants}

A total of 103 completed questionnaires were collected from the CPs in Kedah State, Malaysia. The mean age of participants was 36 years. More than $50 \%$ of them were female. The ethnic groups of the participants were Chinese (59.2 $\%)$, Malay (33.0 \%) and Indian (7.8\%). The participants were having a median of 9 years of pharmacy practices experiences and most of them were graduated from public universities (61.2\%). Table 1 shows the demographic data of the participants.

Table 1: Demographic profile of participants

\begin{tabular}{lccc}
\hline Variable/ltem & Category & Frequency & $\%$ \\
\hline \multirow{2}{*}{ Gender } & Female & 65 & 63.1 \\
& Male & 38 & 36.9 \\
\multirow{2}{*}{ Ethnic } & Chinese & 61 & 59.2 \\
& Malay & 34 & 33.0 \\
\multirow{3}{*}{ University } & Indian & 8 & 7.8 \\
& Public & 63 & 61.2 \\
& Private & 40 & 38.8 \\
\hline
\end{tabular}

Perceptions of community pharmacists on topical antibacterial drug dispensing

More than half of the participating CPs (55/103 or $53.4 \%$ perceived that topical antibacterial drug was not a must for every topical bacterial infection. CPs identified the following three factors as the main factors influencing their dispensing of topical antibacterial drugs: (1) previous clinical experiences (35\%), (2) practice guidelines (27.2 \%) and (3) cost of medications $(19.4 \%)$. Besides that, most of them (84/103 or $81.6 \%$ did not support to switch topical antibacterial drugs to OTC products. CPs in Kedah state perceived that patient's information gathering using WWHAM mnemonic as well as 
patient counselling were important whereby the result was as shown in Table 2.

\section{Experiences of community pharmacists on topical antibacterial drug dispensing}

When CPs were asked to identify the most frequently dispensed topical antibacterial drugs, fusidic acid $(31.1 \%)$ was found to be the highest, followed by neomycin (25.2 \%) and mupirocin $(20.4 \%)$ as shown in Figure 1. Besides that, CPs also identified the most common bacterial skin infections to be superficial wounds $(21.30 \%)$, conjunctivitis (17.52 \%) as well as bed sores/ pressure sores (13.74 \%) as shown in Figure 2. On top of that, majority of CPs in Kedah state prefer to dispense single topical antibacterial drugs and occasionally combinations with steroids. The main reason for them to dispense topical antibacterial drugs combinations was identified to be due to the cost-effectiveness of the products. The result was as shown in Table 3.

In response to the questions related to CPs' confidence in distinguishing topical bacterial infections, patients' counselling as well as dispensing appropriately, they responded using a 5 point scale where $1=$ not confident at all, and 5 $=$ confident. The choices made by pharmacist were displayed as percentage shown in Table 4 whereby most of the CPs in Kedah state showed confident in the activities mentioned previously.

Table 2: Perception of community pharmacists on WWHAM mnemonics and patient counselling during the dispensing of topical antibacterial drugs

\begin{tabular}{|c|c|c|c|}
\hline \multirow[b]{2}{*}{ Variable } & \multicolumn{3}{|c|}{$\mathbf{N}(\%)$} \\
\hline & Important & $\begin{array}{l}\text { Moderately } \\
\text { important }\end{array}$ & Less important \\
\hline \multicolumn{4}{|l|}{ WWHAM mnemonics } \\
\hline Review of patients' symptoms & $103(100 \%)$ & 0 & 0 \\
\hline Asking the duration of symptoms & $89(86.4 \%)$ & $14(13.6 \%)$ & 0 \\
\hline Asking the past medical/medication history & $74(71.8 \%)$ & $29(28.2 \%)$ & 0 \\
\hline $\begin{array}{l}\text { Asking the actions taken beforehand for the } \\
\text { condition }\end{array}$ & $66(64.1 \%)$ & $34(33.0 \%)$ & $3(2.9 \%)$ \\
\hline \multicolumn{4}{|l|}{ Patient counselling } \\
\hline $\begin{array}{l}\text { Inform patients about the dispensed drug } \\
\text { indication }\end{array}$ & $98(95.1 \%)$ & $5(4.9 \%)$ & 0 \\
\hline Inform patients about the direction of use & $97(94.2 \%)$ & $6(5.8 \%)$ & 0 \\
\hline Inform patients about the duration of treatment & $90(87.4 \%)$ & $13(12.6 \%)$ & 0 \\
\hline $\begin{array}{l}\text { Advice patients not to use the drug longer than } \\
\text { the duration instructed }\end{array}$ & $71(68.9 \%)$ & $28(27.2 \%)$ & $4(3.9 \%)$ \\
\hline $\begin{array}{l}\text { If no improvement is seen, advice patients to } \\
\text { consult doctor }\end{array}$ & $85(82.5 \%)$ & $18(17.5 \%)$ & 0 \\
\hline $\begin{array}{l}\text { If affected area becomes swollen or bleeds } \\
\text { after using, advice patients to consult doctor }\end{array}$ & 94 (91.3 \%) & $8(7.8 \%)$ & $1(1.0 \%)$ \\
\hline
\end{tabular}

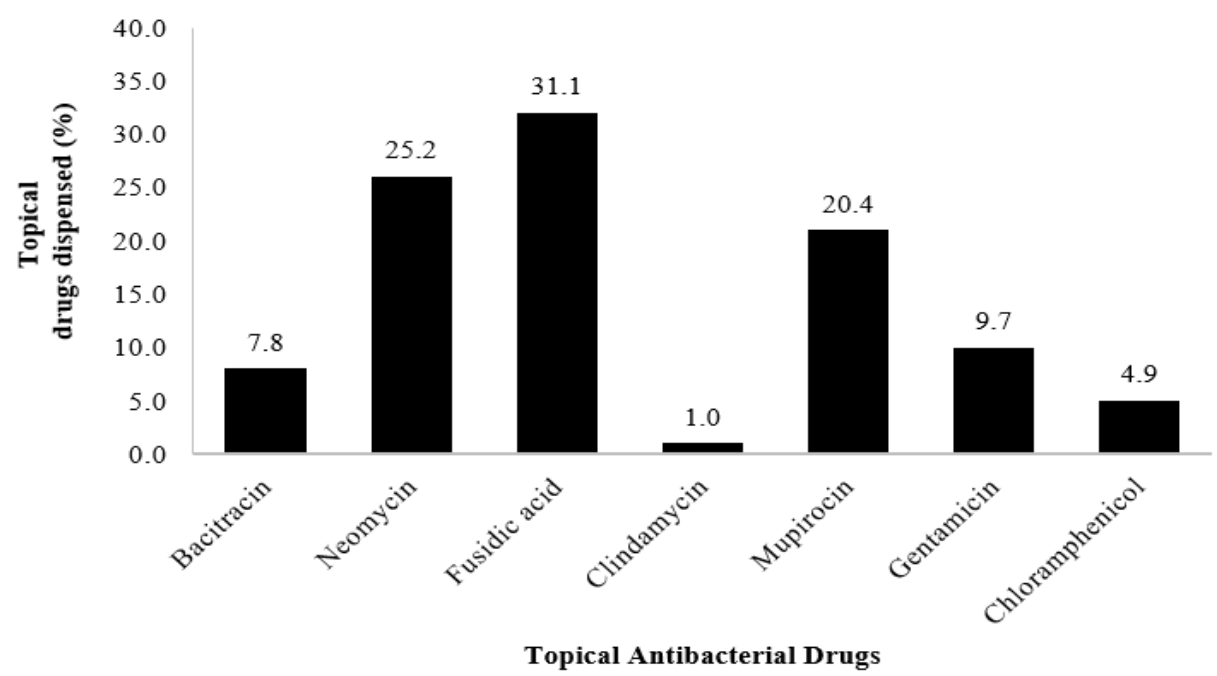

Figure 1: Most frequently dispensed topical antibacterial drugs in Kedah, Malaysia 


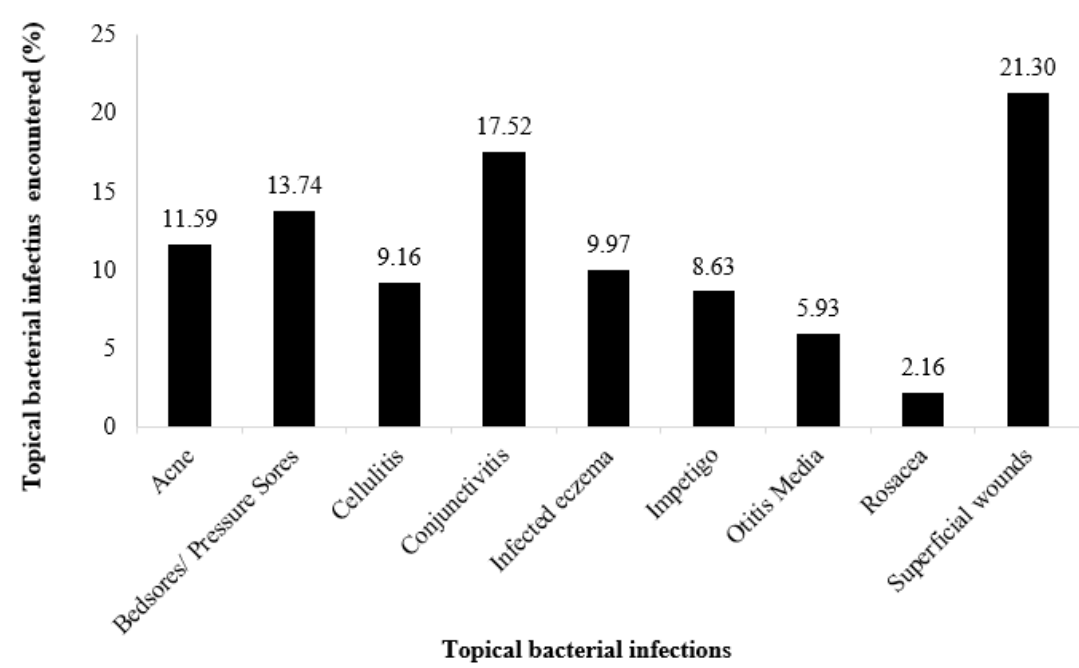

Figure 2: Topical bacterial infections encountered in Kedah, Malaysia

Table 3: Reason of community pharmacists on the selection of topical antibacterial drugs

\begin{tabular}{llcc}
\hline Variable/ltem & Category & N & $\%$ \\
\hline $\begin{array}{l}\text { Preferences of single/ } \\
\text { combination topical } \\
\text { antibacterial drugs }\end{array}$ & Combination with steroids & 48 & 46.6 \\
& $\begin{array}{l}\text { Combinations of two or more topical } \\
\text { antibacterial drugs }\end{array}$ & 2 & 1.9 \\
& Single topical antibacterial drug & 53 & 51.5 \\
Reasons for choosing & More effective & 38 & 36.9 \\
topical antibacterial drug & Causes less resistance & 18 & 17.5 \\
combination & Patients' preferences & 22 & 21.4 \\
& Less cost than sole agent & 4 & 3.9 \\
& Availability of products & 12 & 11.7 \\
& Others & 9 & 8.7 \\
\hline
\end{tabular}

Table 4: Level of confidence of community pharmacists in Kedah, Malaysia

\begin{tabular}{lllccc}
\hline Variable & \multicolumn{5}{c}{ Level of confidence (\%) } \\
\cline { 2 - 6 } & $\mathbf{1}$ & $\mathbf{2}$ & $\mathbf{3}$ & $\mathbf{4}$ & $\mathbf{5}$ \\
\hline $\begin{array}{l}\text { Distinguishing topical bacterial } \\
\text { infections }\end{array}$ & 0 & 0 & 8.7 & 71.8 & 19.4 \\
$\begin{array}{l}\text { Counselling and advising patient on } \\
\text { topical antibacterial drugs }\end{array}$ & 0 & 0 & 10.7 & 44.7 & 44.7 \\
$\begin{array}{l}\text { Dispensing appropriate topical } \\
\text { antibacterial drugs }\end{array}$ & 0 & 0 & 9.7 & 56.3 & 34.0 \\
\hline
\end{tabular}

Majority of CPs (62 \%) did not encounter patient's complaints of side effects of topical antibacterial drugs while $32 \%$ stated that they did. The results obtained show that $12.6 \%$ of CPs encountered antibacterial resistance issues but none of them reported to the respective authorities while $87.4 \%$ did not encounter any; no CP reported any encountered resistance issue.

\section{DISCUSSION}

The result of this study provides an empirical view on the perceptions and experiences of CPs on the dispensing of topical antibacterial drugs in Kedah state, Malaysia. In this study, majority of the CPs perceived that topical antibacterial drug was not a must for every topical bacterial infection. This was supported by several studies which mentioned that topical antibacterial drug was not necessary to improve therapeutic outcomes since minor topical bacterial infections were usually self-limiting which can resolve with proper debridement and hygiene care [11-13]. Although more than half of the CPs in Kedah state had the right perceptions, however, there were still considerable number of them (46.6\%) had the opposite view. This may expose the patients' to the unnecessary use of topical antibacterial drugs and eventually increased the risks of antibacterial resistances.

Besides that, majority of the CPs in Kedah state were of the opinion that topical antibacterial drugs should not be switched to OTC products. 
This was supported by several studies that stated when such drugs were made available over the counter, wider availability will increased the risk of drug misuse and consequently drive the emergence of antibacterial resistances [7,14]. Moreover, patient were often not well trained as healthcare professionals, they may make wrong self-diagnosis which leads to the treatment failure [14]. The result of this study implied that CPs were aware about the negative impacts that may cause by deregulating topical antibacterial drugs to OTC products.

On the other hand, gathering patients' information before dispensing was very important as study stated that this would help in decision making [15]. Effective communication between CPs and patients not only enhanced the use of medications, it also ensure optimal therapeutic outcomes [16]. In this study, majority of the CPs felt that WWHAM mnemonics and patient counselling were important while dispensing topical antibacterial drugs. Nonetheless, WWHAM mnemonic was not purposely designate to establish the diagnosis of diseases, thus, CPs should always keep themselves up-todate to have a strong basic knowledge on managing topical bacterial infections [15].

Based on the experiences of CPs in Kedah, the most frequently dispensed topical antibacterial drug was fusidic acid. Meanwhile, the most frequently encountered topical bacterial infection was identified to be superficial wounds. With Staphylococcus aureus being the ordinary pathogen in most of the infected wounds, fusidic acid had been suggested as an effective treatment by several studies $[17,18]$. Besides that, articles also supported that fusidic acid provides a relatively good penetration rate as it possessed a steroid like structure that enable it to maintain high concentration at the site of infections [17,18]. All these may explain why fusidic acid appeared to be the most frequent dispensed topical antibacterial drugs in Kedah state. However, studies had shown that increased and prolonged usage of topical fusidic acid treatment had led to the increase of antibacterial resistance rates which stressed the judicious use of topical antibacterial drugs by healthcare professional especially CPs [19-22].

Several topical antibacterial drugs had reported to show bacterial resistance by several studies, for instances, mupirocin, fusidic acid, clindamycin and neomycin [22-24]. In this study, CPs in Kedah state encountered antibacterial resistance issue with neomycin. The reason behind may be due to the frequent usage of neomycin as it appeared to be the second highest topical antibacterial drugs dispensed in community pharmacies. Studies claimed that the ability of neomycin to bind to the fatty acid of the skin was responsible for the emergences of antibacterial resistances as it enhances the survival of neomycin-resistant strains on the skin surface [24,25]. Although $12.60 \%$ of CPs encountered antibacterial resistance issue, none of them reported the cases. This showed that CPs in Kedah state had low vigilance on antibacterial issue which may be due to the lack of knowledge on the reporting system available in Malaysia.

\section{Limitations of the study}

This study was a cross-sectional study carried out within a short period among community pharmacists in Kedah State and the sample size was small; thus, the results is not be sufficient to represent all CPs practicing in Malaysia. Besides, comparisons were not carried out due to the lack of previous studies on dispensing of topical antibacterial drugs in community pharmacy settings in Malaysia.

\section{CONCLUSION}

The findings of this study constitute important baseline data that may help in developing future topical antibacterial guidelines to improve dispensing practice and combat drug resistance issues in Malaysia. CPs should be vigilant to enable them detect bacterial resistance as they are suited for adverse event monitoring and reporting. Extended studies using random sampling technique in other states of Malaysia would be helpful in providing a clearer picture of this issue across community settings in Malaysia.

\section{ACKNOWLEDGEMENT}

The authors wish to express their sincere thanks to IMU-Joint Committee of the Research and the Ethics Committee, International Medical University for funding this study.

\section{REFERENCES}

1. Hay $R$, Johns $N$, Williams $H$, Bolliger I, Dellavalle $R$, Margolis $D$, Marks $R$, Naldi $L$, Weinstock $M$, Wulf $S$, Mischaud C, Murray $C$, Naghavi M. The global burden of skin disease in 2010: An analysis of the prevalence and impact of skin conditions. J Investig Dermatol. 2013; 134(6): 1527-1534.

2. Basra MKA, Shahrukh M. Burden of skin diseases. Expert Rev of Pharmacoeconomics Outcomes Res. 2009; 9(3): 271-283.

3. Tognetti L, Martinelli C, Berti S, Hercogova J, Lotti T, Leonicini F, Moretti S. Bacterial skin and soft tissue 
infections: review of the epidemiology, microbiology, aetiopathogenesis and treatment: $A$ collaboration between dermatologists and infectivologists. J Eur Acad Dermatol Venereol. 2012; 26(8): 931-941.

4. Gethin G. Role of topical antimicrobials in wound management. J Wound Care. 2009; 4-8.

5. Tucker R. An exploratory study of UK community pharmacists' perceptions of the skin conditions they encounter: Prevalence, reasons for referral and overthe-counter dermatological wish list. Self-care. 2013; 4(1): 3-17.

6. Azmi S, Nazri N, Azmi A. Extending the roles of community pharmacists: views from general medical practitioners. Med J Malaysia. 2012; 67(6): 577-581.

7. Roque $F$, Soares $S$, Breitenfeld L, López-Durán A, Figueiras $A$, Herdeiro M. Attitudes of community pharmacists to antibiotic dispensing and microbial resistance: a qualitative study in Portugal. Int J Clin Pharm. 2013; 35(3): 417-424.

8. Wabe NT, Raju NJ, Angamo MT. Knowledge, attitude and practice of patient medication counselling among drug dispensers in North West Ethiopia. J App Pharm Sci. 2011; 1(7): 85-90.

9. Elston D. Topical antibiotics in dermatology: emerging patterns of resistance. Dermatol Clin. 2009; 27(1): 2531.

10. Theuretzbacher $U$. Accelerating resistance, inadequate antibacterial drug pipelines and international responses. Int J Antimicrob Agents. 2012; 39(4): 295-299.

11. De Bont EG, Van Loo IH, Dukers - Muijrers NH, Hoebe CJ, Bruggeman CA, Dinant GJ, Cals JW. Oral and topical antibiotic prescriptions for children in general practice. Arch Dis Child. 2013; 98(3): 228-231.

12. Davis $H$, Mant $D$, Scott $C$, Lasserson $D$, Rose PW. Relative impact of clinical evidence and OTC prescribing on topical antibiotic use for acute infective conjunctivitis. Br J Gen Pract. 2009; 59(569): 897-900.
13. Lipsky B, Hoey C. Topical antimicrobial therapy for treating chronic wounds. Clin Infect Dis. 2009; 49(10): 1541-1549.

14. Anghel I, Craciun C. Self-medication with over-thecounter drugs and antibiotics in Romanian consumers: A qualitative study. Cognit, Brain, Behav. 2013; 17(3): 215-23

15. Rutter P, Patel J. Decision making by community pharmacists when making an over-the-counter diagnosis in response to a dermatological presentation. Self-Care. 2013; 4 (6): 125-133.

16. McDonough RP, Bennett MS. Improving Communication Skills of Pharmacy Students through effective percepting. Am J Pharm Educ. 2006; 70(3): 12-58.

17. Wilkinson J. Fusidic acid in dermatology. Br J Dermatol. 1998; 139: 37-40.

18. Schwartz R, Al Mutairi N. Topical antibiotics in dermatology: An update. GJDV. 2010; 17(1), 1-19.

19. Shah M, Mohanraj M. High levels of fusidic acid-resistant Staphylococcus aureus in dermatology patients. BrJ Dermatol. 2003; 148(5): 1018-1020.

20. Gelmetti C. Local antibiotics in dermatology. Dermatol Ther. 2008; 21 (3): 187-195.

21. Heng $Y$, Tan $K$, Sen $P$, Chow $A$, Leo $Y$, Lye D, Chan $R$. 'Staphylococcus aureus and topical fusidic acid use: results of a clinical audit on antimicrobial resistance', Int J Dermatol. 2013; 52(7): 876-881.

22. Jarvis $B$. Use of topical antibiotic formulations and resistance: is there a link? CPJ. 2002; 135(8):16-20.

23. Espersen. Resistance to antibiotics used in dermatological practice. Br J Dermatol. 1998; 139: 4-8.

24. Macdonald R, Beck M. Neomycin: a review with particular reference to dermatological usage, Clin Exp Dermatol. 1983; 8(3): 249-258.

25. Lacey $R$. Loss of the antibacterial action of skin after topical neomycin. Br J Dermatol. 1969; 81(6): 435-439. 